\title{
Ring-Opening Polymerization of $\varepsilon$-Caprolactone Using Novel Dendritic Aluminum Alkoxide Initiators
}

\author{
Takahito MuraKI, Ken-ichi FuJITA, ${ }^{\dagger}$ Akihiro OIsHI, and Yoichi TAGUCHI \\ National Institute of Advanced Industrial Science and Technology (AIST), \\ AIST Tsukuba Central 5, 1-1-1, Higashi, Tsukuba 305-8565, Japan
}

(Received June 29, 2005; Accepted July 20, 2005; Published November 15, 2005)

\begin{abstract}
We have prepared two novel dendritic aluminum alkoxide initiators for ring-opening polymerization. An aluminum trialkoxide dendrimer was prepared from triethylaluminum and dendritic alcohol, and an aluminum dendrimer embedded by bidentate ligation of the dendritic $\alpha$-glycol was prepared from diethylaluminum ethoxide and a novel dithiothreitol-derived dendritic ligand. These aluminum dendrimers were each applied as an initiator for ringopening polymerization of $\varepsilon$-caprolactone, and each one showed high reactivity. Furthermore, when the dithiothreitol-derived dendrimer was used as the initiator, the higher the generation from which the dendrimer was derived, the narrower the polydispersity $\left(M_{\mathrm{w}} / M_{\mathrm{n}}\right)$ of poly( $\varepsilon$-caprolactone) was. This relationship between the generation of the dendritic initiator and polydispersity is one of the positive dendritic effects. [DOI 10.1295/polymj.37.847]

KEY WORDS Dendrimer / Ring-opening Polymerization / Poly( $\varepsilon$-caprolactone) / Dendritic Effect /
\end{abstract}

Recent concerns about the environment call for the development of environmentally benign materials. One of the most practical materials is biodegradable aliphatic polyesters, such as poly( $\varepsilon$-caprolactone) (PCL) and poly(lactide). ${ }^{1} \mathrm{PCL}$ is generally prepared by ring-opening polymerization of $\varepsilon$-caprolactone $(\varepsilon-\mathrm{CL})$ through the use of metal alkoxides such as aluminum triisopropoxide ${ }^{2}$ and titanium tetrabutoxide ${ }^{3}$ as initiators. However, the reactivity of these initiators is rather low, though they are easily available. Moreover, by employing them, both $\varepsilon$-CL, which is a monomer, and the ester group of the obtained polyester chain are activated to cause transesterification, so that the polydispersity $\left(M_{\mathrm{w}} / M_{\mathrm{n}}\right)$ of PCL is broadened. Recently, in experiments aiming to achieve rapid ring-opening polymerization, new initiators such as rare earth alkoxide ${ }^{4}$ and rare earth trifluoromethanesulfonate ${ }^{5}$ have been investigated. Furthermore, to suppress transesterification and to activate only the monomer (Figure 1), bulky group-introduced initiators such as mono(cyclopentadienyl)titanium complex ${ }^{6}$ rare earth diethyl acetoacetate complex ${ }^{7}$ and titanium bisphenoxide complex ${ }^{8}$ have been developed to provide the PCL with narrow $M_{\mathrm{w}} / M_{\mathrm{n}}$. When these initiators are used, block copolymerization of $\varepsilon$-CL with another lactone has also been achieved by the sequential addition of monomers. ${ }^{4 b, 7}$ Very recently, we have found that dendritic aluminum alkoxide is effective for narrowing the $M_{\mathrm{w}} / M_{\mathrm{n}}$ of PCL. ${ }^{9}$

Dendrimers are fascinating macromolecules by virtue of their unique physical and chemical properties, and have well-defined three-dimensional structures. ${ }^{10}$

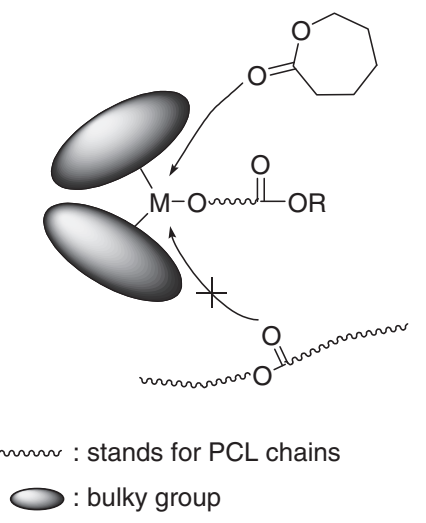

Figure 1. Suppression of the transesterification by bulky group at propagation site.

Because of these properties, encapsulation of reactive metals into the interior of a dendrimer can improve its reactivity as well as the selectivity for the substrate, both as a result of the dendron's steric effect. ${ }^{11}$ Herein, we report a very simple method of preparing two types of novel aluminum alkoxide dendrimers, in which the aluminum is positioned at the core. We also discuss the ring-opening polymerization of $\varepsilon$-CL using these dendrimers as initiators. Moreover, we reveal the positive dendritic effect on the relationship between the generation of the dendritic initiator and the $M_{\mathrm{w}} / M_{\mathrm{n}}$ of the obtained PCL.

\section{EXPERIMENTAL}

\section{Materials}

First- and second-generation dendrons (G1-OH,

${ }^{\dagger}$ To whom correspondence should be addressed (E-mail: k.fujita@aist.go.jp). 
G1-Br, G2-OH, G2-Br), 3,5-dihydroxybenzyl alcohol, 18-crown-6, carbon tetrabromide, and DL-dithiothreitol were purchased from Tokyo Kasei Kogyo Co., Ltd. and were used as received. Triphenyl phosphine, methyl iodide, and dry solvents (acetone, tetrahydrofuran (THF), toluene, and ethanol) were purchased from Wako Pure Chemicals Industries Ltd. Potassium carbonate was purchased from Nippon Soda Co., Ltd. $\varepsilon$-Caprolactone was purchased from Aldrich and was distilled from $\mathrm{CaH}_{2}$ under reduced pressure. Triethylaluminum and diethylaluminum ethoxide were purchased from Aldrich Chemical Company, Inc.

\section{Measurements}

Microanalyses were performed with a CE Instruments EA1110 elemental analyzer. IR spectra were recorded on a Thermo Electron Nicolet Nexus 470 FT-IR spectrophotometer. ${ }^{1} \mathrm{H}$ and ${ }^{13} \mathrm{C}$ NMR spectra were measured with a JEOL LA-500 spectrometer $\left({ }^{1} \mathrm{H}: 500 \mathrm{MHz},{ }^{13} \mathrm{C}: 125 \mathrm{MHz}\right)$.

Chemical shifts are reported as ppm downfield from TMS in $\delta$ unit. Mass spectra were measured with JEOL MS 600H (FAB) and Shimadzu AXIMA-CFR (MALDI-TOF) mass spectrometers. The matrix of mass spectra (FAB) was 3-nitrobenzyl alcohol. Melting points were determined on a Yanaco MP-500D melting point apparatus, and uncorrected. Kieselgel 60 F254 (Merck) was used for TLC, and Wakogel C-300 (Wako) was used for silica gel column chromatography. Number-average molecular weights $\left(M_{\mathrm{n}}\right)$ and polydispersity $\left(M_{\mathrm{w}} / M_{\mathrm{n}}\right)$ were measured by means of gel permeation chromatography (GPC) on a Tosoh 8020 GPC system with a refractive index detector. A combination of two TSKgel GMH $\mathrm{XL}_{\mathrm{XL}}$ columns (Tosoh, $7.8 \mathrm{~mm} \times 30 \mathrm{~cm}$ ) was used. The columns were eluted by chloroform (flow rate of $1 \mathrm{~mL} \mathrm{~min}^{-1}$ at $40^{\circ} \mathrm{C}$ ) and were calibrated with polystyrene standards.

\section{Preparations of Dendritic Alcohols and Dendritic Bromides}

The synthetic procedures to prepare dendritic alcohols 2[G3], 2[G4] and dendritic bromides 1[G3], 1[G4] employed here were modified from Aida's synthetic method. ${ }^{12}$

\section{Preparation of the Third-generation Dendritic Alco- hol 2[G3]}

A dry acetone solution $(80 \mathrm{~mL})$ of 3,5-dihydroxybenzyl alcohol $(685.3 \mathrm{mg}, 4.89 \mathrm{mmol}), 3,5$-bis(3,5-dimethoxybenzyloxy)benzyl bromide 1[G2] $(5.166 \mathrm{~g}$, $10.3 \mathrm{mmol})$, anhydrous potassium carbonate $(1.690 \mathrm{~g}$, $12.2 \mathrm{mmol}$ ), and 18 -crown-6 (304.6 mg, $1.15 \mathrm{mmol})$ was refluxed for $6 \mathrm{~h}$ under an argon atmosphere. The reaction mixture was filtered with Celite to remove inorganic salts, and the filtrate was evaporated to dryness. The residue was purified with silica gel column chromatography (toluene/ethyl acetate $=4 / 1$ as eluent) to obtain the third-generation dendritic alcohol 2[G3] $(4.508 \mathrm{~g}, 4.58 \mathrm{mmol})$ in $94 \%$ yield.

The fourth-generation dendritic alcohol 2[G4] was obtained in $93 \%$ yield in a similar manner.

\section{Preparation of the Third-generation Dendritic Bro- mide 1[G3]}

To a dry THF solution $(16 \mathrm{~mL})$ of the third-generation dendritic alcohol 2[G3] $(4.477 \mathrm{~g}, 4.54 \mathrm{mmol})$ and carbon tetrabromide $(1.656 \mathrm{~g}, 4.99 \mathrm{mmol})$ was added triphenylphosphine $(1.311 \mathrm{~g}, 5.00 \mathrm{mmol})$, and the reaction mixture was stirred under argon while being monitored by TLC. If necessary, additional aliquots of carbon tetrabromide and triphenylphosphine were added at $c a .15 \mathrm{~min}$ intervals to force the completion of the reaction. The reaction mixture was filtered with Celite, and the filtrate was evaporated to dryness. The residue was purified with silica gel column chromatography (toluene/ethyl acetate $=30 / 1$ as eluent) to obtain the third-generation dendritic bromide 1[G3] $(4.717 \mathrm{~g}, 4.50 \mathrm{mmol})$ in $99 \%$ yield.

The fourth-generation dendritic bromide 1[G4] was obtained in $96 \%$ yield in a similar manner.

\section{Preparation of Aluminum Trialkoxide Dendrimer 3}

Typical procedure: To a dry toluene solution $(3 \mathrm{~mL})$ of the second-generation dendritic alcohol 2[G2] $(198.8 \mathrm{mg}, 0.451 \mathrm{mmol})$ was added a $0.388 \mathrm{M}$ triethylaluminum toluene solution $(0.385 \mathrm{~mL}, 0.15 \mathrm{mmol})$, and the reaction solution was stirred for $2.0 \mathrm{~h}$ at room temperature to prepare the corresponding aluminum trialkoxide dendrimer $\mathbf{3}[\mathbf{G 2}]$.

\section{Ring-opening Polymerization of $\varepsilon$-Caprolactone Using 3 as Initiator}

Typical procedure: The toluene solution of dendritic initiator 3[G2], which was prepared according to the above procedure, was added to a dry toluene solution $(12 \mathrm{~mL})$ of $\varepsilon$-caprolactone $(1.870 \mathrm{~g}, 16.38 \mathrm{mmol})$ at room temperature under an argon atmosphere. After stirring the resulting mixture for $30 \mathrm{~min}$, which was monitored by TLC, ring-opening polymerization was completed. After removal of the toluene, chloroform $(5 \mathrm{~mL})$ was added to the polymerization mixture. To methanol $(500 \mathrm{~mL})$ this chloroform solution of polymerization mixture was added dropwise, followed by the addition of $10 \%$ methanolic hydrochloric acid $(10 \mathrm{~mL})$. The resulting precipitate was filtered, washed with a large amount of methanol, and dried at room temperature for $15 \mathrm{~h}$ in vacuo to obtain poly ( $\varepsilon$-caprolactone) in $84 \%$ yield $(1.777 \mathrm{~g})$. 
Preparation of Dithiothreitol-derived Ligand 4

Typical procedure: To a dry ethanol solution $(5 \mathrm{~mL})$ of sodium hydroxide (109.2 mg, $2.73 \mathrm{mmol}$ ) was added DL-dithiothreitol $(154.1 \mathrm{mg}, 0.999 \mathrm{mmol})$ to provide the corresponding sodium thiolate. After stirring for $10 \mathrm{~min}$, a dry THF solution $(15 \mathrm{~mL})$ of 3,5-dimethoxybenzyl bromide 1[G1] (488.71 mg, $2.11 \mathrm{mmol}$ ) was added, and the reaction solution was stirred for $3.5 \mathrm{~h}$. After evaporation of the reaction mixture, the residue was purified with silica gel column chromatography (toluene/ethyl acetate $=4 / 1$ as eluent) to obtain $S, S^{\prime}$-bis(3,5-dimethoxybenzyl)-DL-dithiothreitol 4[G1] (446.8 mg, $0.983 \mathrm{mmol}$ ) in $98 \%$ yield.

4[G1]: white powder; m.p. $76.0-76.6^{\circ} \mathrm{C}$; IR $\left(\mathrm{CH}_{2} \mathrm{Cl}_{2}\right)$ 3444, 2936, 2837, 1597, 1463, 1205, 1155, 1064, 834 $\mathrm{cm}^{-1} ;{ }^{1} \mathrm{H} \mathrm{NMR}\left(\mathrm{CDCl}_{3}\right) \delta(\mathrm{ppm}) 6.47(\mathrm{~d}, J=2.3 \mathrm{~Hz}$, $4 \mathrm{H}, \mathrm{ArH}), 6.35$ (t, $J=2.3 \mathrm{~Hz}, 2 \mathrm{H}, \mathrm{ArH}), 3.78$ (s, 12H, $\left.\mathrm{OCH}_{3}\right), 3.66$ (s, 4H, SCH$\left.H_{2} \mathrm{Ar}\right), 3.64-3.61$ (m, 2H, $\left.\mathrm{CH}_{2} \mathrm{CH}(\mathrm{OH})\right), 2.66-2.57$ (m, 6H, $\left.\mathrm{SCH} \mathrm{CH}_{2} \mathrm{OH}\right)$; ${ }^{13} \mathrm{C} \mathrm{NMR}\left(\mathrm{CDCl}_{3}\right) \delta(\mathrm{ppm}) 160.9,140.2,106.9,99.3$, 70.6, 55.3, 36.6, 35.4; FAB MS for $\mathrm{C}_{22} \mathrm{H}_{31} \mathrm{O}_{6} \mathrm{~S}_{2} \mathrm{~m} / \mathrm{z}$ Calcd: $455\left[(\mathrm{M}+\mathrm{H})^{+}\right]$; Found: 455; Anal. Calcd for $\mathrm{C}_{22} \mathrm{H}_{30} \mathrm{O}_{6} \mathrm{~S}_{2}$ : C, 58.12; H, 6.65; S, 14.11\%. Found: $\mathrm{C}$, 58.13 ; H, 6.66; S, $14.15 \%$.

4[G2]: white powder; m.p. 47.0-47.8 ${ }^{\circ} \mathrm{C}$; IR $\left(\mathrm{CH}_{2} \mathrm{Cl}_{2}\right)$ 3478, 2936, 2838, 1597, 1462, 1205, 1155, 1050, 833 $\mathrm{cm}^{-1} ;{ }^{1} \mathrm{H} \mathrm{NMR}\left(\mathrm{CDCl}_{3}\right) \delta(\mathrm{ppm}) 6.57-6.54(\mathrm{~m}, 12 \mathrm{H}$, $\operatorname{ArH}), 6.49(\mathrm{t}, J=2.0 \mathrm{~Hz}, 2 \mathrm{H}, \mathrm{ArH}), 6.40(\mathrm{t}, J=2.3$ $\mathrm{Hz}, 4 \mathrm{H}, \mathrm{ArH}), 4.94$ (s, 8H, OCH $\mathrm{Ar}$ ), 3.77 (s, 24H, $\left.\mathrm{OCH}_{3}\right), 3.63$ (s, 4H, SCH$\left.H_{2} \mathrm{Ar}\right), 3.61-3.59$ (m, 2H, $\left.\mathrm{CH}_{2} \mathrm{CH}(\mathrm{OH})\right), 2.61-2.53\left(\mathrm{~m}, 6 \mathrm{H}, \mathrm{SCH} \mathrm{CH}_{2} \mathrm{OH}\right)$; ${ }^{13} \mathrm{C} \mathrm{NMR}\left(\mathrm{CDCl}_{3}\right) \delta(\mathrm{ppm}) 161.0,160.0,140.4,139.2$, 108.1, 105.3, 101.1, 99.9, 70.7, 70.0, 55.4, 36.6, 35.3; FAB MS for $\mathrm{C}_{54} \mathrm{H}_{63} \mathrm{O}_{14} \mathrm{~S}_{2} \mathrm{~m} / z$ : Calcd: $999[(\mathrm{M}+$ $\mathrm{H})^{+}$]; Found: 999; Anal. Calcd for $\mathrm{C}_{54} \mathrm{H}_{62} \mathrm{O}_{14} \mathrm{~S}_{2}: \mathrm{C}$, 64.91; H, 6.25; S, 6.42\%. Found: C, 65.04; H, 6.29; $\mathrm{S}, 6.29 \%$.

4[G3]: colorless glass; IR $\left(\mathrm{CH}_{2} \mathrm{Cl}_{2}\right)$ 3492, 2938, 2838, 1597, 1430, 1205, 1155, 1052, $833 \mathrm{~cm}^{-1}$; ${ }^{1} \mathrm{H}$ NMR $\left(\mathrm{CDCl}_{3}\right) \delta(\mathrm{ppm}) 6.64(\mathrm{~d}, J=2.1 \mathrm{~Hz}, 8 \mathrm{H}, \mathrm{ArH}), 6.55-$ $6.52(\mathrm{~m}, 24 \mathrm{H}, \operatorname{Ar} H), 6.46(\mathrm{t}, J=2.1 \mathrm{~Hz}, 2 \mathrm{H}, \operatorname{Ar} H)$, $6.39(\mathrm{t}, J=2.1 \mathrm{~Hz}, 8 \mathrm{H}, \mathrm{ArH}), 4.92\left(\mathrm{~s}, 16 \mathrm{H}, \mathrm{OCH}_{2} \mathrm{Ar}\right)$, $4.90\left(\mathrm{~s}, 8 \mathrm{H}, \mathrm{OCH}_{2} \mathrm{Ar}\right), 3.76\left(\mathrm{~s}, 48 \mathrm{H}, \mathrm{OCH}_{3}\right), 3.61-$ 3.59 (m, 6H, SCH$\left.H_{2} \mathrm{Ar}, \mathrm{CH}_{2} \mathrm{CH}(\mathrm{OH})\right), 2.60-2.52(\mathrm{~m}$, $\left.\left.6 \mathrm{H}, \quad \mathrm{SCH} \mathrm{CH}_{2} \mathrm{CH}\right)\right) ;{ }^{13} \mathrm{C} \mathrm{NMR}\left(\mathrm{CDCl}_{3}\right) \delta(\mathrm{ppm})$ 160.9, 160.0, 139.2, 139.1, 108.0, 106.4, 105.2, 101.6, 101.0, 99.9, 70.6, 70.0, 69.9, 55.3, 36.6, 35.3; MALDI-TOF MS for $\mathrm{C}_{118} \mathrm{H}_{126} \mathrm{O}_{30} \mathrm{~S}_{2} \mathrm{Na} m / z$ : Calcd: $2109.77\left[(\mathrm{M}+\mathrm{Na})^{+}\right]$; Found: 2110.56; Anal. Calcd for $\mathrm{C}_{118} \mathrm{H}_{126} \mathrm{O}_{30} \mathrm{~S}_{2}$ : C, 67.86; H, 6.08; S, 3.07\%. Found: C, 67.82; H, 5.93; S, 2.90\%.

4[G4]: colorless glass; IR $\left(\mathrm{CH}_{2} \mathrm{Cl}_{2}\right)$ 2937, 2838, 1597 , $1458,1205,1155,1052,832 \mathrm{~cm}^{-1} ;{ }^{1} \mathrm{H} \mathrm{NMR}\left(\mathrm{CDCl}_{3}\right)$ $\delta(\mathrm{ppm}) 6.62(\mathrm{~d}, J=2.1 \mathrm{~Hz}, 16 \mathrm{H}, \mathrm{ArH}), 6.60(\mathrm{~d}, J=$ $2.1 \mathrm{~Hz}, 8 \mathrm{H}, \mathrm{ArH}), 6.52-6.49$ (m, 48H, ArH), 6.45 (t,
$J=2.1 \mathrm{~Hz}, 2 \mathrm{H}, \operatorname{Ar} H), 6.36(\mathrm{t}, J=2.1 \mathrm{~Hz}, 16 \mathrm{H}, \mathrm{Ar} H)$, 4.89 (s, 32H, OCH $\mathrm{OH}_{2} \mathrm{Ar}, 4.86\left(\mathrm{~s}, 16 \mathrm{H}, \mathrm{OCH}_{2} \mathrm{Ar}\right), 4.85$ (s, 8H, OCH$\left.H_{2} \mathrm{Ar}\right), 3.73\left(\mathrm{~s}, 96 \mathrm{H}, \mathrm{OCH}_{3}\right), 3.59-3.54$ (m, 6H, SCH $\mathrm{Ar}_{2} \mathrm{CH}_{2} \mathrm{CH}(\mathrm{OH})$ ), 2.55-2.50 (m, 6H, $\left.\mathrm{SCH} \mathrm{H}_{2} \mathrm{CH}(\mathrm{OH})\right) ;{ }^{13} \mathrm{C} \mathrm{NMR}\left(\mathrm{CDCl}_{3}\right) \delta$ (ppm) 161.0, 160.0, 139.2, 139.1, 108.0, 106.4, 105.2, 101.6, 101.0, 99.9, 70.6, 70.0, 69.9, 55.3, 36.6, 35.3; MALDI-TOF MS for $\mathrm{C}_{246} \mathrm{H}_{254} \mathrm{O}_{62} \mathrm{~S}_{2} \mathrm{Na} m / z$ : Calcd: $4286.61[(\mathrm{M}+$ $\mathrm{Na})^{+}$]; Found: 4288.26; Anal. Calcd for $\mathrm{C}_{246} \mathrm{H}_{254^{-}}$ $\mathrm{O}_{62} \mathrm{~S}_{2}$ : C, 69.25; H, 6.00; S, 1.50\%. Found: C, 69.62; H, 6.08; S, $1.43 \%$.

\section{Preparation of 4 [Me]}

To a dry ethanol solution $(5 \mathrm{~mL})$ of sodium hydroxide $(200.9 \mathrm{mg}, 5.02 \mathrm{mmol})$ was added DL-dithiothreitol $(308.1 \mathrm{mg}, 2.00 \mathrm{mmol})$ to provide the corresponding sodium thiolate. After stirring for $10 \mathrm{~min}$, methyl iodide $(604.2 \mathrm{mg}, 4.26 \mathrm{mmol})$ was added, and the reaction solution was stirred for $2.0 \mathrm{~h}$. After evaporation of the reaction mixture, the residue was purified with silica gel column chromatography (chloroform/ethyl acetate $=1 / 1$ as eluent) to obtain $S, S^{\prime}$-dimethyl-DLdithiothreitol 4[Me] $(356.4 \mathrm{mg}, 1.96 \mathrm{mmol})$ in $98 \%$ yield.

4[Me]: white powder; m.p. 73.0-74.0 ${ }^{\circ} \mathrm{C}$; IR $\left(\mathrm{CH}_{2} \mathrm{Cl}_{2}\right)$ $3224,2914,1425,1310,1223,1038,968 \mathrm{~cm}^{-1}$; ${ }^{1} \mathrm{H}$ NMR $\left(\mathrm{CDCl}_{3}\right) \delta(\mathrm{ppm}) 3.77-3.72\left(\mathrm{~m}, 2 \mathrm{H}, \mathrm{CH}_{2-}\right.$ $\mathrm{CH}(\mathrm{OH})), 2.77-2.69\left(\mathrm{~m}, 6 \mathrm{H}, \mathrm{SCH}_{2} \mathrm{CH}(\mathrm{OH})\right), 2.15$ $\left(\mathrm{s}, 6 \mathrm{H}, \mathrm{SCH}_{3}\right) ;{ }^{13} \mathrm{C} \mathrm{NMR}\left(\mathrm{CDCl}_{3}\right) \delta(\mathrm{ppm}) 70.0,38.4$, 15.6; Anal. Calcd for $\mathrm{C}_{6} \mathrm{H}_{14} \mathrm{O}_{2} \mathrm{~S}_{2}$ : C, 39.53; H, 7.74; S, 35.18\%. Found: C, 39.73; H, 7.69; S, 35.28\%.

Preparation of Dithiothreitol-derived Aluminum Dendrimer 5

Typical procedure: To a dry toluene solution $(2.5 \mathrm{~mL})$ of dithiothreitol-derived ligand $\mathbf{4}[\mathbf{G 2}]$ (151.4 mg, $0.152 \mathrm{mmol}$ ) was added a $0.314 \mathrm{M}$ diethylaluminum ethoxide toluene solution $(0.48 \mathrm{~mL}, 0.15 \mathrm{mmol})$, and the reaction solution was stirred for $2.0 \mathrm{~h}$ at room temperature to prepare the corresponding dithiothreitolderived aluminum dendrimer 5[G2].

Ring-opening polymerization of $\varepsilon$-caprolactone using thus-prepared $\mathbf{5}$ as the initiator was carried out in a manner similar to that using $\mathbf{3}$.

\section{RESULTS AND DISCUSSION}

In this study we aimed to use the dendritic skeleton as a bulky group to suppress transesterification. We also attempted to use the dendrimer interior as the polymerization field. Recently, a few groups have reported the use of dendritic initiators for the ring-opening polymerization of $\varepsilon$-CL. ${ }^{13}$ However, they did not use the dendrimer interior as the polymerization field; rather, they used the dendritic structure (dendron) only 
as the initiation terminus. In this study, we have designed novel dendritic aluminum alkoxide initiators, in which effective polymerization fields were constructed throughout the propagation step.

To construct perfect, defect-free dendritic structures, the convergent approach ${ }^{10 \mathrm{~d}}$ is generally the best strategy. In the present study, methyl-terminated poly(3,5-disubstituted benzyl ether) dendron, ${ }^{12}$ which was prepared by a convergent method, was selected. The structural formulas of the G1-G4 dendrons are shown in Figure 2.

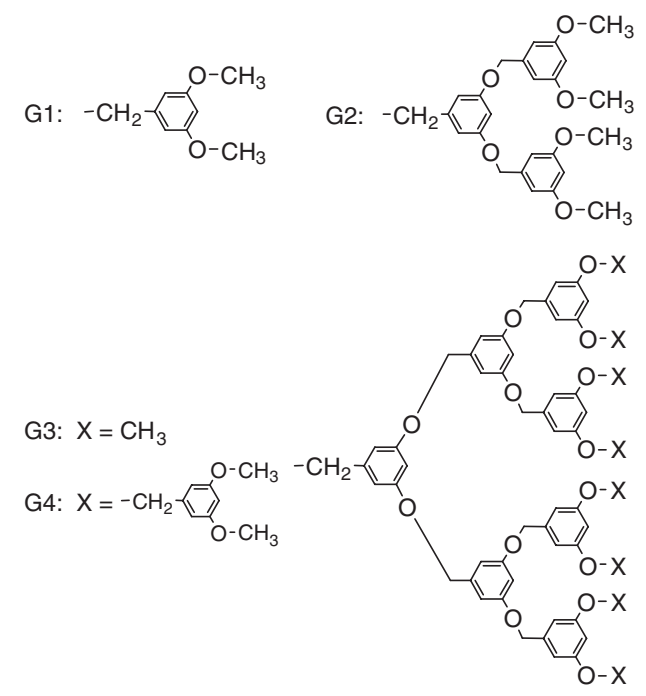

Figure 2. Structural formulas of Gn dendrons $(n=1-4)$.

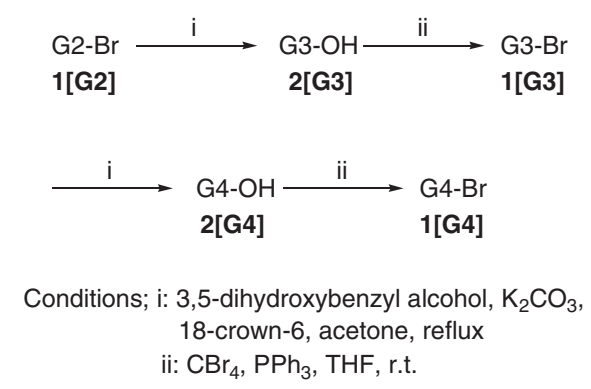

Scheme 1.

The generation growth reaction of the dendrons was carried out according to Scheme 1. To obtain pure dendron in high yield conveniently, the reaction mixture was filtered with Celite instead of the usual extractive workup, and toluene-ethyl acetate was used as an eluent for silica gel column chromatography.

\section{Polymerization of $\varepsilon$-Caprolactone Using Aluminum Trialkoxide Dendrimer 3 as Initiator}

The novel aluminum trialkoxide dendrimer $\mathbf{3}$ was prepared by mixing 3 moles equivalent of dendritic alcohol 2 and triethylaluminum with the evolution of ethane gas, according to Scheme 2.

By employing aluminum trialkoxide dendrimer $\mathbf{3}$ as

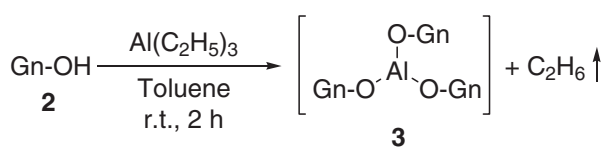

Scheme 2.

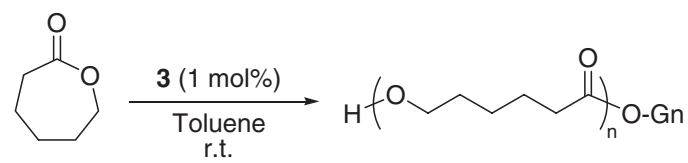

Scheme 3.

Table I. Ring-opening polymerization of $\varepsilon$-CL using 3 as initiator

\begin{tabular}{|c|c|c|c|c|c|c|c|}
\hline Entry & 3 & $\begin{array}{c}{[\varepsilon-\mathrm{CL}]_{0}{ }^{\mathrm{a}}} \\
(\mathrm{mol} / \mathrm{L})\end{array}$ & $\begin{array}{l}\text { Time } \\
\text { (min.) }\end{array}$ & $\begin{array}{c}\text { Conversion } \\
\text { (\%) }\end{array}$ & $M_{\mathrm{n}}{ }^{\mathrm{c}}$ & $M_{\mathrm{w}} / M_{\mathrm{n}}^{\mathrm{c}}$ & $\begin{array}{c}\text { Yield }^{\mathrm{d}} \\
(\%)\end{array}$ \\
\hline 1 & 3 [G1] & 1.0 & 45 & 97 & 11,000 & 1.31 & 91 \\
\hline 2 & 3 [G2] & 1.0 & 30 & 87 & 10,000 & 1.26 & 84 \\
\hline 3 & $3[\mathrm{G} 3]$ & 1.0 & 30 & 99 & 9,000 & 1.42 & 93 \\
\hline 4 & 3[G4] & 1.0 & 15 & 99 & 10,000 & 1.31 & 93 \\
\hline 5 & $3[\mathrm{G1}]$ & 0.5 & 120 & 96 & 9,000 & 1.21 & 89 \\
\hline 6 & 3 [G2] & 0.5 & 120 & 91 & 8,000 & 1.15 & 85 \\
\hline 7 & 3[G3] & 0.5 & 120 & 90 & 8,000 & 1.19 & 88 \\
\hline 8 & $3[\mathbf{G 4}]$ & 0.5 & 120 & 68 & 7,000 & 1.14 & 68 \\
\hline
\end{tabular}

${ }^{a}$ Initial concentration of $\varepsilon$-CL. ${ }^{b}$ Determined by ${ }^{1} \mathrm{H}$ NMR.

${ }^{\mathrm{c}}$ Determined by GPC against polystyrene standard.

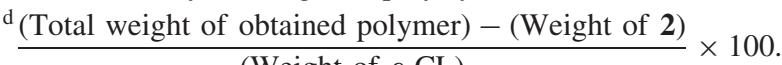

$$
\text { (Weight of } \varepsilon \text {-CL) }
$$

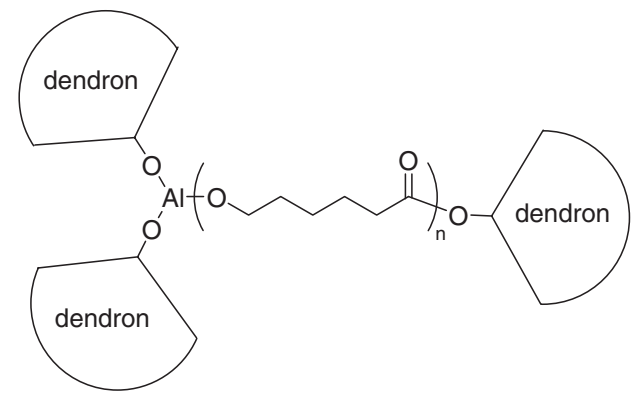

Figure 3. Plausible intermediate of propagation step with use of $\mathbf{3}$ as initiator.

the initiator, we carried out the ring-opening polymerization of $\varepsilon$-CL at room temperature under an argon atmosphere (Scheme 3). The results are shown in Table I. In using $\mathbf{3}$ as the initiator, we found that the dendritic group was located at the initiation terminus of PCL, as revealed by ${ }^{1} \mathrm{H}$ NMR spectra of obtained PCL, which was then purified by preparative GPC to remove $2 .{ }^{14}$ Therefore, it is supposed that a plausible intermediate of the propagation step contains a dendritic aluminum dialkoxide group - $\mathrm{Al}(\mathrm{O}-\mathrm{Gn})_{2}$ at the propagation site (Figure 3).

First, by employing the first-generation-derived dendritic initiator 3[G1], the polymerization time 
was significantly shortened (45 min), compared to that using aluminum triisopropoxide $\mathrm{Al}\left(\mathrm{O}^{i} \mathrm{Pr}\right)_{3}$ as the initiator $(9.5 \mathrm{~h}) .{ }^{15}$ It is supposed that the polymerization ability of a simple aluminum alkoxide such as $\mathrm{Al}\left(\mathrm{O}^{i} \mathrm{Pr}\right)_{3}$ is not so high in general, because its Lewis acidity is decreased by the aggregation of the aluminum alkoxide unit on the basis of the octahedric coordination of an aluminum atom. ${ }^{16}$ Therefore, to increase the Lewis acidity of an aluminum atom, the dissociation of its aggregation by the introduction of a bulky group is very effective. ${ }^{17}$ This high reactivity of the dendritic initiator 3[G1] shows that even the first-generation dendron is bulky enough to suppress the aggregation of the aluminum trialkoxide unit.

Encouraged by this result, we subsequently performed ring-opening polymerization of $\varepsilon$-CL using the higher-generation-derived dendritic initiator $\mathbf{3}$ (Table I, Entries 2-4). Also by use of the higher-generation-derived dendritic initiator $\mathbf{3}$, polymerization was completed in a shorter reaction time. However, no relationship was observed between the generation of the dendritic initiator 3 and the $M_{\mathrm{w}} / M_{\mathrm{n}}$ of PCL, contrary to our expectation about the positive dendritic effect on the $M_{\mathrm{w}} / M_{\mathrm{n}}$.

Next, to reduce the reactivity of the dendritic initiator 3 , which afforded a rapid polymerization, the reaction concentration of $\varepsilon$-CL was changed from 1.0 $\mathrm{mol} / \mathrm{L}$ to $0.5 \mathrm{~mol} / \mathrm{L}$ (Entries $5-8$ ). In these cases, although a long reaction time was required to complete the polymerization, the $M_{\mathrm{w}} / M_{\mathrm{n}}$ was narrowed in all generations. From these results, it was assumed that the broadening of the $M_{\mathrm{w}} / M_{\mathrm{n}}$ of PCL in the cases of entries 1-4 was derived mainly from the high reactivity of the dendritic initiator $\mathbf{3}$, not from the transesterification of the PCL chain.

Polymerization of $\varepsilon$-Caprolactone Using Dithiothreitol-derived Aluminum Dendrimer 5 as Initiator

Even when the aluminum trialkoxide dendrimer $\mathbf{3}$ was used, the $M_{\mathrm{w}} / M_{\mathrm{n}}$ of PCL was not narrowed, although the polymerization time was shortened. We therefore designed a novel dendritic initiator to narrow the $M_{\mathrm{w}} / M_{\mathrm{n}}$.

As the skeleton of a novel dendritic ligand, a glycol skeleton merits attention. Because it can form a rigid structure through the bidentate coordination to an aluminum atom, it is expected to construct an effective polymerization field. Previously, dendritic ligands with a $\omega$-glycol core (TADDOL) have been reported by Seebach et al. However, a multistep reaction was required to prepare them. ${ }^{18}$ We therefore developed a simple method for preparing a dendritic $\alpha$-glycol ligand by using DL-dithiothreitol as the core unit.

As shown in Scheme 4, DL-dithiothreitol-derived dendritic $\alpha$-glycol ligands 4 were prepared by the

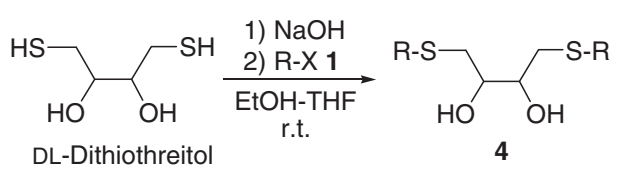

Scheme 4.

Table II. Preparation of dithiothreitol-derived dendritic ligand 4

\begin{tabular}{ccccc}
\hline Entry & R-X & $\begin{array}{c}\text { Time } \\
(\mathrm{h})\end{array}$ & $\mathbf{4}$ & $\begin{array}{c}\text { Yield } \\
(\%)\end{array}$ \\
\hline $1^{\mathrm{a}}$ & $\mathrm{Me}-\mathrm{I}$ & 2.0 & $\mathbf{4}[\mathbf{M e}]$ & 98 \\
2 & $\mathrm{G} 1-\mathrm{Br}$ & 3.5 & $\mathbf{4}[\mathbf{G 1}]$ & 98 \\
3 & $\mathrm{G} 2-\mathrm{Br}$ & 3.5 & $\mathbf{4}[\mathbf{G 2}]$ & 99 \\
4 & $\mathrm{G} 3-\mathrm{Br}$ & 3.0 & $\mathbf{4}[\mathbf{G 3}]$ & 96 \\
5 & $\mathrm{G} 4-\mathrm{Br}$ & 5.0 & $\mathbf{4}[\mathbf{G 4}]$ & 86 \\
\hline
\end{tabular}

${ }^{\mathrm{a}} \mathrm{EtOH}$ was used as solvent.

reaction of DL-dithiothreitol with 1 . Dendritic $\alpha$-glycol ligands $\mathbf{4}$ were obtained in high yields in all cases (Table II).

Then, as shown in Scheme 5, the dithiothreitolderived aluminum dendrimer $\mathbf{5}$ was prepared by mixing the corresponding dendritic $\alpha$-glycol ligand $\mathbf{4}$ and

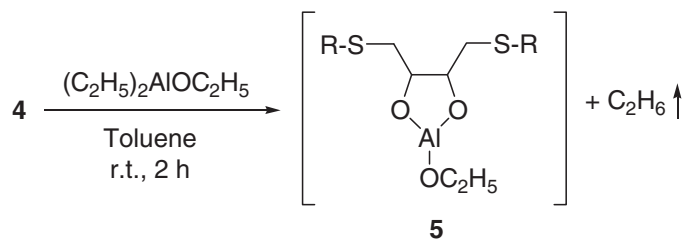

Scheme 5.

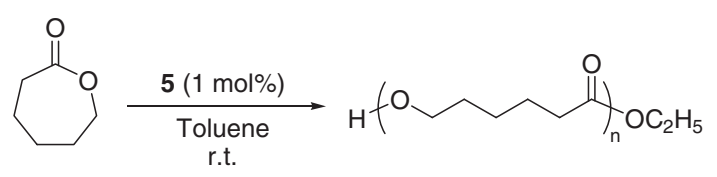

Scheme 6.

Table III. Ring-opening polymerization of $\varepsilon$-CL using 5 as initiator

\begin{tabular}{ccccccc}
\hline Entry & $\mathbf{5}$ & $\begin{array}{c}\text { Time } \\
(\mathrm{h})\end{array}$ & $\begin{array}{c}\text { Conversion } \\
(\%)\end{array}$ & $M_{\mathrm{n}}{ }^{\mathrm{b}}$ & $M_{\mathrm{w}} / M_{\mathrm{n}}{ }^{\mathrm{b}}$ & $\begin{array}{c}\text { Yield }^{\mathrm{c}} \\
(\%)\end{array}$ \\
\hline 1 & $\mathbf{5}[\mathbf{M e}]$ & 1.3 & 96 & 18,000 & 1.18 & 94 \\
2 & $\mathbf{5}[\mathbf{G 1}]$ & 1.5 & 93 & 19,000 & 1.19 & 86 \\
3 & $\mathbf{5}[\mathbf{G} 2]$ & 1.5 & 92 & 22,000 & 1.16 & 85 \\
4 & $\mathbf{5}[\mathbf{G 3}]$ & 1.5 & 94 & 21,000 & 1.16 & 83 \\
5 & $\mathbf{5}[\mathbf{G 4}]$ & 2.5 & 99 & 22,000 & 1.12 & 96 \\
$6^{\mathrm{d}}$ & $\mathbf{5}[\mathbf{G 2}]$ & 2.0 & 86 & 13,000 & 1.14 & 80 \\
$7^{\mathrm{e}}$ & $\mathbf{5}[\mathbf{G 2}]$ & 4.5 & 86 & 25,000 & 1.18 & 86 \\
\hline
\end{tabular}

${ }^{\mathrm{a}}$ Determined by ${ }^{1} \mathrm{H}$ NMR. ${ }^{\mathrm{b}}$ Determined by GPC against polystyrene standard.

$\frac{\mathrm{c} \text { (Total weight of obtained polymer) }- \text { (Weight of } \mathbf{4})}{\text { (Weight of } \varepsilon \text {-CL) }} \times 100$.

${ }^{\mathrm{d}}$ Carried out in THF. ${ }^{\mathrm{e}}$ Performed by use of $0.5 \mathrm{~mol} \%$ initiator. 
diethylaluminum ethoxide with the evolution of ethane as a gas.

Next, by employing dithiothreitol-derived aluminum dendrimer $\mathbf{5}$ as the initiator, we carried out ring-opening polymerization of $\varepsilon$-CL according to Scheme 6. The results are shown in Table III. In using $\mathbf{5}$ as the initiator, it was found that the ethyl group was located at the initiation terminus of PCL, as revealed by ${ }^{1} \mathrm{H}$ NMR spectra of obtained PCL, which was then purified by preparative GPC to remove $4 .{ }^{14}$ It was also found that the PCL chains did not include the dendritic $\alpha$-glycol ligand 4 . From these results, it is supposed that the plausible intermediate of the propagation step contains the dendritic aluminum alkoxide unit at the propagation site, similar to the case when $\mathbf{3}$ was used (Figure 4).

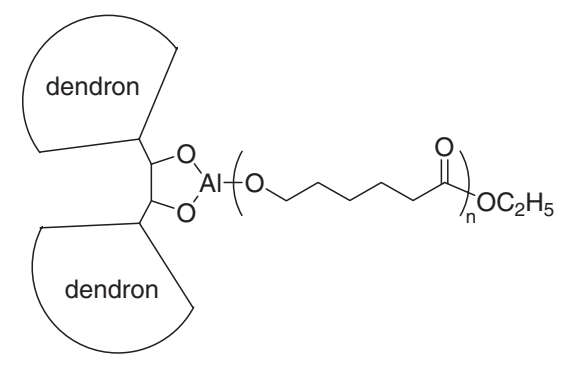

Figure 4. Plausible intermediate of propagation step with use of $\mathbf{5}$ as initiator.

First, by employing $S, S^{\prime}$-dimethylated initiator $\mathbf{5}[\mathrm{Me}]$, which had no dendritic skeleton, the polymerization occurred with unexpected rapidly $(1.3 \mathrm{~h})$. From this result, it is assumed that only the introduction of the bidentate ligand to an aluminum atom suppresses the aggregation of the aluminum alkoxide unit. Thus, the dithiothreitol-derived initiator shows high reactivity even though it has no dendritic skeleton.

We subsequently performed ring-opening polymerization using the dendritic initiator 5 (Table III, Entries 2-5). Also in these cases, polymerization occurred rather rapidly, completing within $1.5-2.5 \mathrm{~h}$. Furthermore, the higher generation-derived initiators 5 showed the narrower polydispersity $\left(M_{\mathrm{w}} / M_{\mathrm{n}}\right)$ of PCL (5[G4]: $M_{\mathrm{w}} / M_{\mathrm{n}}=1.12$, Entry 5). This result is likely due to the suppression of the PCL chain transesterification through coordination of the aluminum core; as a result, only the monomer is activated, due to the quite bulky dendron, especially when a higher-generation-derived initiator is used. This relationship between the generation of dendritic initiator 5 and the $M_{\mathrm{w}} / M_{\mathrm{n}}$ is one of the positive dendritic effects. ${ }^{19}$

With regard to the number-average molecular weights $\left(M_{\mathrm{n}}\right)$, very interesting results were obtained. When a series of dithiothreitol-derived initiator $\mathbf{5}$ was employed, in all cases the $M_{\mathrm{n}}$ of PCL was nearly twice that expected on the basis of the monomer/ initiator ratio. This enlargement of $M_{\mathrm{n}}$ is probably attributable to the tetrahedric coordinative dimerization of the dendritic initiator $\mathbf{5} .{ }^{20}$ Initiator $\mathbf{5}$ is a structurally and polarly nonsymmetrical molecule, which is constituted by a less-polar dendron unit and by a much more polar aluminum ethoxide core unit. Therefore, it is supposed that the aluminum dendrimer $\mathbf{5}$ dimerizes to hide the ethoxide part, especially in a nonpolar solvent such as toluene. On the other hand, carrying out polymerization in THF, PCL was obtained with the expected $M_{\mathrm{n}}$ based on the monomer/initiator ratio (Entry 6). This is probably because the dimerization of 5 is suppressed due to the coordination of THF to an aluminum atom. Moreover, even when polymerization was carried out by the use of $0.5 \mathrm{~mol} \% \mathbf{5}[\mathbf{G 2}]$ as the initiator, the obtained PCL showed the expected $M_{\mathrm{n}}$ based on the monomer/initiator ratio (Entry 7). This is probably because $\varepsilon$-CL works not only as a monomer but also as a co-solvent that possesses coordination ability, and thus the dimerization of $\mathbf{5}[\mathbf{G 2}]$ would be dissociated.
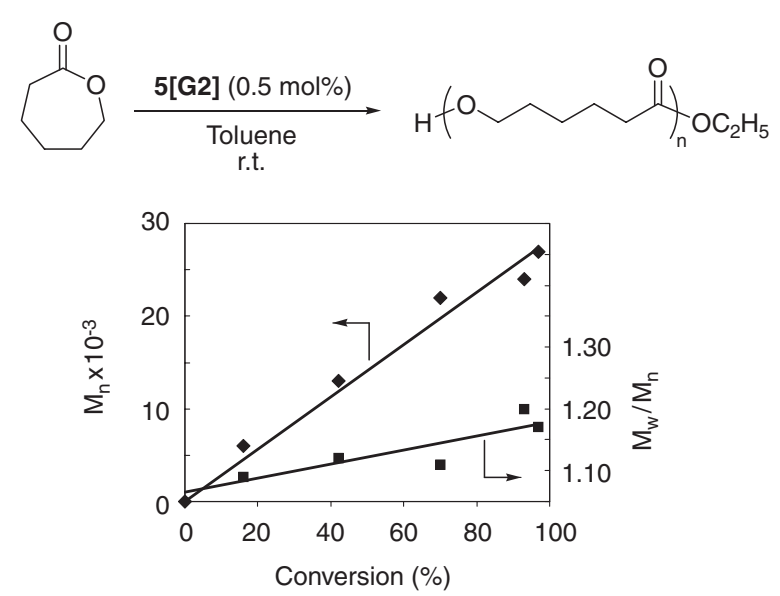

Figure 5. Relationship between conversion and $M_{\mathrm{n}}, M_{\mathrm{w}} / M_{\mathrm{n}}$.

Finally, to follow the relationship between the conversion of $\varepsilon$-CL and the $M_{\mathrm{n}}$, the $M_{\mathrm{w}} / M_{\mathrm{n}}$ of PCL, ringopening polymerization of $\varepsilon$-CL was performed by the use of $0.5 \mathrm{~mol} \%$ dendritic initiator 5[G2]. As shown in Figure 5, the $M_{\mathrm{n}}$ of PCL increases linearly with the conversion of $\varepsilon$-CL. The $M_{\mathrm{w}} / M_{\mathrm{n}}$ of PCL remained narrow throughout the polymerization. These results indicate that this ring-opening polymerization of $\varepsilon$ $\mathrm{CL}$ is a living polymerization.

\section{CONCLUSIONS}

We have prepared two novel types of dendritic aluminum alkoxide initiators - an aluminum trialkoxide dendrimer and a dithiothreitol-derived aluminum alkoxide dendrimer - for the ring-opening polymeriza- 
tion of $\varepsilon$-CL. The polymerization ability of these two types of dendritic initiators was high due to the suppression of the aggregation of the aluminum alkoxide unit. Furthermore, the dithiothreitol-derived aluminum dendritic initiator showed a positive dendritic effect on the relationship between the generation of the dendritic initiator and the polydispersity $\left(M_{\mathrm{w}} / M_{\mathrm{n}}\right)$ of PCL. This molecular design of a polymerization initiator, in which a dendritic group is introduced to the active site, is expected to be very useful.

Acknowledgment. This work was supported by Industrial Technology Research Grant Program in '04 from New Energy and Industrial Technology Development Organization (NEDO) of Japan and by the research grant from Mitsui Chemicals, Inc.

\section{REFERENCES}

1. a) K. M. Stridsberg, M. Ryner, and A. C. Albertsson, $A d v$. Polym. Sci., 157, 41 (2002).

b) A. C. Albertsson and I. K. Varma, Adv. Polym. Sci., 157, 1 (2002).

c) Y. Ikeda and H. Tsuji, Macromol. Rapid Commun., 21, 117 (2000).

2. C. Jacobs, P. Dubois, R. Jerome, and P. Teyssie, Macromolecules, 24, 3027 (1991).

3. H. R. Kricheldorf, M. Berl, and N. Scharnagl, Macromolecules, 21, 286 (1988).

4. a) E. Martin, P. Dubois, and R. Jerome, Macromolecules, 33, 1530 (2000).

b) M. Nishiura, Z.-M. Hou, T. Koizumi, T. Imamoto, and Y. Wakatsuki, Macromolecules, 32, 8245 (1999).

c) M. Yamashita, Y. Takemoto, E. Ihara, and H. Yasuda, Macromolecules, 29, 1798 (1996).

5. N. Nomura, A. Taira, T. Tomioka, and M. Okada, Macromolecules, 33, 1497 (2000).

6. J. Okuda and I. L. Rushkin, Macromolecules, 26, 5530 (1993).

7. Y. Shen, Z. Shen, Y. Zhang, and K. Yao, Macromolecules, 29, 8289 (1996).

8. D. Takeuchi, T. Nakamura, and T. Aida, Macromolecules, 33, 725 (2000).

9. K. Fujita, T. Muraki, T. Sakurai, A. Oishi, and Y. Taguchi, Chem. Lett., 34, 1180 (2005).

10. a) J. M. J. Frechet and D. A. Tamalia, Ed., "Dendrimers and Other Dendritic Polymers," John Wiley \& Sons, New York, 2002.

b) G. R. Newkome, C. N. Moorefield, and F. Vogtle, "Dendrimers and Dendrons," Wiley-VCH, Weinheim,
2001.

c) P. A. Chase, R. J. M. K. Gebbink, and G. van Koten, J. Organomet. Chem., 689, 4016 (2004).

d) J. M. J. Frechet, J. Polym. Sci., Part A: Polym. Chem., 41, 3713 (2003).

11. a) K. R. Gopidas, J. K. Whitesell, and M. A. Fox, J. Am. Chem. Soc., 125, 14168 (2003).

b) D. L. Stone, G. M. Dykes, and D. K. Smith, Dalton Trans., 2003, 3902.

c) L. J. Twyman, A. S. H. King, and I. K. Martin, Chem. Soc. Rev., 31, 69 (2002).

d) R. Kreiter, A. W. Kleij, R. J. M. K. Gebbink, and G. van Koten, Top. Curr. Chem., 217, 163 (2001).

e) S. M. Waybright, K. McAlpine, M. Laskoski, M. D. Smith, and U. H. F. Bunz, J. Am. Chem. Soc., 124, 8661 (2002).

f) D. Astruc and F. Chardac, Chem. Rev., 101, 2991 (2001). g) B. S. Balaji, Y. Obora, D. Ohara, S. Koide, and Y. Tsuji, Organometallics, 20, 5342 (2001).

12. Y. Tomoyose, D.-L. Jiang, R.-H. Jin, T. Aida, T. Yamashita, and K. Horie, Macromolecules, 29, 5236 (1996).

13. a) I. Gitsov, P. T. Ivanova, and J. M. J. Frechet, Maclomol. Rapid Commun., 15, 387 (1994).

b) I. D. Mecerreyes, P. Dubois, R. Jerome, J. L. Hedrick, and C. J. Hawker, J. Polym. Sci., Part A: Poly. Chem., 37, 1923 (1999).

14. Initiator could be easily separated from precipitated polymer mixture by preparative GPC using JAIGEL-2H, $2.5 \mathrm{H}$ column.

15. Conversion: $97 \%, M_{\mathrm{n}}: 12,000, M_{\mathrm{w}} / M_{\mathrm{n}}: 1.19$, Yield: $93 \%$.

16. N. Ropson, P. Dubois, R. Jerome, and P. Teyssie, Macromolecules, 26, 6378 (1993).

17. K. Maruoka, T. Itoh, M. Sakurai, K. Nonoshita, and H. Yamamoto, J. Am. Chem. Soc., 110, 3588 (1988).

18. a) H. Sellner, P. B. Rheiner, and D. Seebach, Helv. Chem. Acta, 85, 352 (2002).

b) P. B. Rheiner and D. Seebach, Chem. Eur. J., 5, 3221 (1999).

c) P. B. Rheiner, H. Sellner, and D. Seebach, Helv. Chem. Acta, 80, 2027 (1997).

19. a) B. Yi, Q.-H. Fan, G.-J Deng, Y.-M. Li, L.-Q. Qin, and A. S. C. Chan, Org. Lett., 6, 1361 (2004).

b) A. Dahan and M. Portnoy, Org. Lett., 5, 1197 (2003).

c) A. W. Kleij, R. A. Grossage, R. J. M. K. Gebbink, N. Brinkmann, E. J. Reijerse, U. Kragl, M. Lutz, A. L. Spek, and G. van Koten, J. Am. Chem. Soc., 122, 12112 (2000). d) P. Bhyrappa, J. K. Young, J. S. Moore, and K. S. Suslick, J. Am. Chem. Soc., 118, 5708 (1996).

e) P. Bhyrappa, J. K. Young, J. S. Moore, and K. S. Suslick, J. Mol. Catal. A: Chem., 113, 109 (1996).

20. I. Taden, H.-C. Kang, W. Massa, T. P. Spaniol, and J. Okuda, Eur. J. Inorg. Chem., 2000, 441 (2000). 